\title{
Influence of two different inhalation devices on therapy compliance in asthmatic patients
}

\section{Constant Paul van Schayck, Ingrid Desirée Bijl-Hofland, Hans Folgering, Sonja Gerarda Martina Cloosterman, Reinier Akkermans, Frank V.D. Elshout} \& Chris van Weel

To cite this article: Constant Paul van Schayck, Ingrid Desirée Bijl-Hofland, Hans Folgering, Sonja Gerarda Martina Cloosterman, Reinier Akkermans, Frank V.D. Elshout \& Chris van Weel (2002) Influence of two different inhalation devices on therapy compliance in asthmatic patients, Scandinavian Journal of Primary Health Care, 20:2, 126-128, DOI: 10.1080/pri.20.2.126.128

To link to this article: http://dx.doi.org/10.1080/pri.20.2.126.128
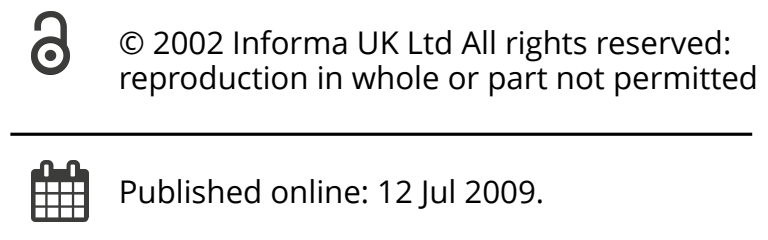

Submit your article to this journal

Џlll Article views: 130

à

View related articles $ک$ 


\title{
Influence of two different inhalation devices on therapy compliance in asthmatic patients
}

\author{
Constant Paul van Schayck ${ }^{1,2}$, Ingrid Desirée Bijl-Hofland ${ }^{1}$, Hans Folgering ${ }^{3}$, Sonja Gerarda \\ Martina Cloosterman ${ }^{1}$, Reinier Akkermans ${ }^{1}$, Frank v.d. Elshout ${ }^{4}$ and Chris van Weel $^{1}$ \\ ${ }^{1}$ Department of General Practice and Social Medicine, University of Nijmegen, ${ }^{2}$ Department of General Practice, \\ University of Maastricht, ${ }^{3}$ Department of Pulmonary Diseases, Dekkerswald, University of Nijmegen, ${ }^{4}$ Department of \\ Pulmonary Diseases, Rijnstate Hospital, Arnhem, The Netherlands.
}

\section{Scand J Prim Health Care 2002;20:126-128. ISSN 0281-3432}

Objective - To examine the influence of inhalation device (Autohaler versus metered dose inhaler) and patients' subjective opinion towards the different devices, as well as daily frequency and duration of treatment on medication compliance.

Design - Prospective study measuring compliance in the same patients of the Autohaler twice daily with the metered dose inhaler twice daily, as well the Autohaler twice daily with the Autohaler four times daily.

Setting - Primary health care.

Subjects - 34 subjects with asthma.

Main outcome measures - Patients preference and compliance. Results - Patients preferred the Autohaler. The percentage of patients with a negative opinion towards the metered dose inhaler was $38 \%$ compared with $12 \%$ towards the Autohaler. The median values of the compliance rate of the Autohaler with twice and four times daily frequency were $90.8 \%(25-75$ th percentile $61.6-98.0 \%)$ and $78.5 \%(25-75$ th percentile $49.0 \%-91.2 \%)$, respectively $(p<0.001)$. The duration of treatment period had a significant negative influence on compliance when four times daily dosage frequency was prescribed $(\mathrm{p}=\mathbf{0 . 0 5})$.

Conclusion - In conclusion, the devices (metered dose inhaler and Autohaler) and the patients' opinion about the devices did not significantly contribute to the compliance rates. Compliance towards the medication treatment, however, is negatively influenced by a high daily frequency.

Key words: asthma, compliance, inhalation device.

Chris van Weel, Department of General Practice and Social Medicine, University of Nijmegen, P.O. Box 9101, 6500 HB Nijmegen, The Netherlands. E-mail: T.Jeijsman@hsv.kun.nl
Non-compliance occurs particularly in patients with chronic illness and with variable symptoms over time, as in asthma. Non-compliance in asthma might contribute to its morbidity (1). In order to prevent poor compliance and prescribe effectively, physicians should take into account treatment factors that contribute to poor compliance.

The breath-actuated inhaler (Autohaler) is a device that is triggered by the inspiratory airflow produced by the patient. It is easier to use than the metered dose inhaler (MDI), because patients are not dependent on hand-lung coordination, which could influence compliance. We therefore studied the effect of the inhalation device (Autohaler and MDI) on medication compliance in asthmatic patients and determined the influence on compliance of patients' subjective opinion about both devices.

Patients with chronic airflow obstruction often use different drugs in combination with regimen requiring multiple daily dosage during a long period. It is known that a prescribed frequent daily use results in poor compliance $(2,3)$. We investigated the compliance rates with different daily frequency by means of an Autohaler, which we expected to show a more positive effect on compliance compared with the MDI. We also investigated the effect of duration of treatment on the degree of compliance.

\section{MATERIAL AND METHODS \\ Patients}

Asthmatic patients were recruited from a research project investigating the effect of bronchodilator treatment on airflow sensitivity in a placebo-controlled design (4). Patients used three inhalers daily, two Autohalers and one MDI, over a period of 12 weeks. One Autohaler had to be used twice daily, the other four times daily. The MDI had to be used twice daily. Extensive instruction on how to use the different devices was given by a lung function technician before the start of the trial. The trial was approved by the Ethics Committee of the University of Nijmegen and informed consent was obtained from each patient.

\section{Assessment of medication compliance}

Medication was weighed before and after use in order to assess the amount used. Devices were collected without prior announcement (5) and new ones delivered 6 weeks after the start of the trial during a regular visit to the homes of patients. Furthermore, medication was collected when the patient visited the laboratory at the end of the study period. Medication compliance rates were expressed as: medication used as a percentage of medication prescribed. 
Patients' opinions towards the inhalation device

After 6 weeks, we sought the subjective opinions of patients about the different devices by asking the following question: "What do you think about use of the device?" This question was asked for each different type of device. Patients' subjective opinions were divided into three groups: inconvenient, neutral and convenient.

\section{Analysis}

Differences were analysed by Wilcoxon test if the compliance rates were not normally distributed. Values are expressed as medians with $25-75$ th percentile ranges.

\section{Power}

A clinically relevant difference of $12.5 \%$ in medication compliance $(1,5)$ can be detected with an $\alpha$ of 0.05 and a $\beta$ of 0.20 and a standard deviation of $25 \%$ with a sample size of at least 34 subjects.

\section{RESULTS}

\section{Patients}

The total number of patients meeting the inclusion criteria was 34 , which was sufficient for the power needed. Their mean age was 37 (SD 13) years, 19 were women, $\mathrm{PC}_{20}$ (geometric mean) was $0.92 \mathrm{mg}$ histamine/ $\mathrm{ml}(95 \% \mathrm{CI} 0.48-1.75), \mathrm{FEV}_{1} \%$ of predicted was $80 \%$ (SD 18).

\section{Medication compliance}

The median value of the compliance rate of the total amount of medication used, expressed as a percentage of the prescribed medication, was $87.1 \%$ (25-75th percentile $61.8 \%-94.6 \%$ ). In $65 \%$ of the patients, compliance rates were between $80 \%$ and $120 \%$. Underuse (less than $80 \%$ of the prescribed dose) was far more common than overuse (above $120 \%$ of the prescribed dose), in $34 \%$ and $1.0 \%$ of the patients, respectively.

\section{Effect of device, daily frequency and treatment period}

There was no effect of device on medication compliance $(p=0.317)$. The median values for the compliance rate of the MDI and the Autohaler (with twice daily frequency) were $95.7 \%$ (25-75th percentile $83.9-$ $99.9 \%$ ) and $90.8 \%$ (25-75th percentile 61.6-98.0\%), respectively. The median values for the compliance rate of the Autohaler with twice and four times daily frequency were $90.8 \%(25-75$ th percentile $61.6-$ $98.0 \%)$ and $78.5 \%$ (25-75th percentile $49.0-91.2 \%)$, respectively, and differed significantly $(p=0.001)$. There was a significant effect of treatment period on medication compliance in the Autohaler that had to be used four times daily $(\mathrm{p}=0.05)$. The median compliance percentage of the Autohaler (four times daily) was $79.6 \%(25-75$ th percentile $54.8-90.8 \%)$ in the first 6 weeks of the trial and $75.6 \%$ (25-75th percentile $48.4-90.7 \%$ ) in the second half of the study period.

\section{Patients' opinions towards the MDI and the autohaler}

The numbers of patients who evaluated their device as inconvenient, neutral and convenient are presented in Fig. 1. The mean compliance percentage in patients with a negative opinion towards the MDI and the Autohaler was $83 \%(\mathrm{SD}=30 \%)$ and $61 \%(\mathrm{SD}=39 \%)$, respectively. In patients with a positive opinion towards the MDI and the Autohaler, compliance rates were $77 \%(\mathrm{SD}=38 \%)$ and $74 \%(\mathrm{SD}=35 \%)$, respectively.

\section{DISCUSSION}

The results of the present study show that there was no difference in compliance between the two different inhalation devices (MDI and Autohaler). This contrasts with our expectation that patients would be more compliant with use of the Autohaler than with use of the MDI. A possible explanation could be that the Autohaler is a relatively new device compared with the MDI, and some patients might be relatively unfamiliar with it. There were more patients who disliked the MDI than there were patients who found the Autohaler inconvenient. Opinions about the devices, however, did not seem to have an influence on medication compliance. A corresponding conclusion has been found by Arshad et al. (6), who reported that no significant

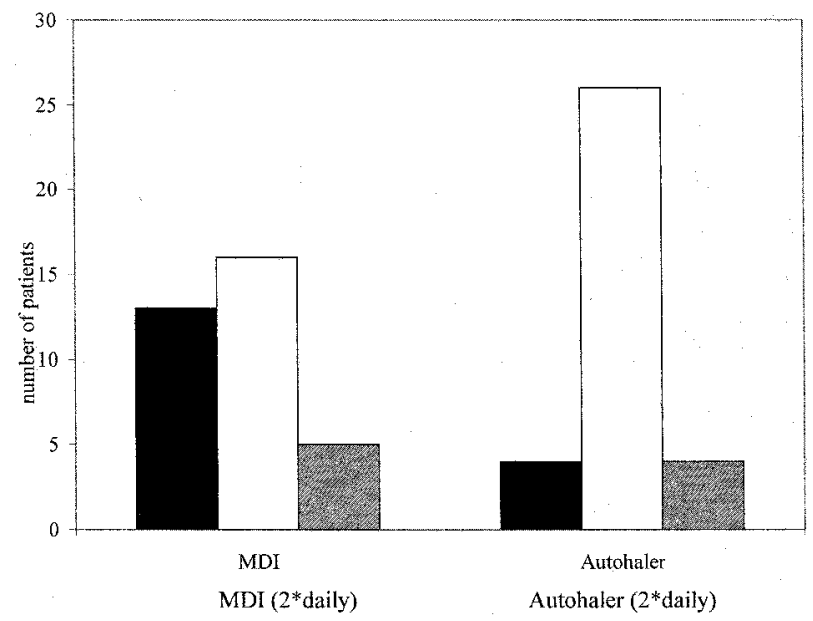

Fig. 1. Patients' subjective opinions concerning the inhalation device $(\mathrm{n}=34, \mathrm{MDI}=$ metered dose inhaler) ( $\boldsymbol{\square}=$ inconvenient; $\square=$ neutral; $=$ convenient). 
difference was identified between the Autohaler and the MDI in respect of bronchodilator usage.

In this study, we observed that the most important factor for compliance was the relatively highly prescribed frequency of four times daily. It has been reported earlier that compliance is reduced when daily dosage is doubled (2). Therefore, when the impact of compliance is included in determining medication treatment, a low daily frequency is obviously preferable to a high daily frequency. This is relevant for medical care when we compare, for instance, short-acting with long-acting bronchodilators. In conclusion, the devices (MDI and Autohaler) and patients' opinions about the devices did not significantly contribute to the compliance rates. Compliance towards medication treatment, however, is negatively influenced by high daily frequency.

\section{REFERENCES}

1. Horn CR, Clark TJH, Cochrane GM. Compliance with inhaled therapy and morbidity from asthma. Respir Med 1990;84:67-70.

2. Mann MC, Eliasson O, Patel K, ZuWallack RL. An evaluation of severity-modulated compliance with q.i.d. dosing of inhaled beclomethasone. Chest 1992;102:1342-6.

3. Tashkin DP. Multiple dose regimens: impact on compliance. Chest 1995; 107:176s-82s.

4. Cloosterman SGM, Schermer TRJ, Hofland ID, van der Heide S, Brunekreef B, van den Elshout FJJ, et al. Effects of house dust mite avoidance measures on Der $\mathrm{p} 1$ concentrations and clinical condition of mild adult house dust mite-allergic asthmatic patients, using no inhaled steroids. Clin Exp All 1999;29:1336-46.

5. Dompeling E, van Grunsven PM, van Schayck CP, Folgering $\mathrm{H}$, Molema $\mathrm{J}$, van Weel $\mathrm{C}$. Treatment with inhaled steroids in asthma and chronic bronchitis: long-term compliance and inhaler technique. Fam Pract 1992;9:161-6.

6. Arshad H, Luyt D, Goodwin A, Jones A, Hide D, Williams I. Sodium cromoglycate via inhaler and autohaler. Respir Med 1993;87:299-302. 